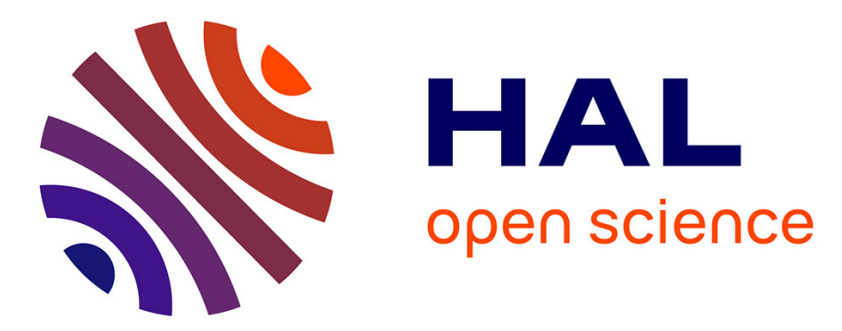

\title{
Exploring Axisymmetric Shape-Change's Purposes and Allure for Ambient Display: 16 Potential Use Cases and a Two-Month Preliminary Study on Daily Notifications
}

\author{
Maxime Daniel, Guillaume Rivière
}

\section{- To cite this version:}

Maxime Daniel, Guillaume Rivière. Exploring Axisymmetric Shape-Change's Purposes and Allure for Ambient Display: 16 Potential Use Cases and a Two-Month Preliminary Study on Daily Notifications. TEI ' 21 Work in Progress, The Fifteenth ACM International Conference on Tangible, Embedded and Embodied Interaction, Feb 2021, Salzburg, Austria. 10.1145/3430524.3442452 . hal-03040877

\section{HAL Id: hal-03040877 https://hal.science/hal-03040877}

Submitted on 18 Dec 2020

HAL is a multi-disciplinary open access archive for the deposit and dissemination of scientific research documents, whether they are published or not. The documents may come from teaching and research institutions in France or abroad, or from public or private research centers.
L'archive ouverte pluridisciplinaire HAL, est destinée au dépôt et à la diffusion de documents scientifiques de niveau recherche, publiés ou non, émanant des établissements d'enseignement et de recherche français ou étrangers, des laboratoires publics ou privés. 
TEI'2021 ( ACM, 2021. This is the author's version of the work. It is posted here by permission of ACM for your personal use. Not for redistribution. The definitive Version of Record is published in the Proceedings of the Fifteenth International Conference on Tangible, Embedded, and Embodied Interaction, https://doi.org/10.1145/3430524.3442452

\section{Exploring Axisymmetric Shape-Change's Purposes and Allure for Ambient Display: 16 Potential Use Cases and a Two-Month Preliminary Study on Daily Notifications}

\author{
Maxime Daniel \\ m.daniel@estia.fr \\ Univ. Bordeaux, ESTIA INSTITUTE OF TECHNOLOGY \\ F-64210 Bidart, France
}

\begin{abstract}
In the last decade, HCI research has proposed promising technologies for shape-changing interfaces. The usefulness and the user experience of shape-change are, however, still to be explored and understood. This paper extends the understanding of the potential utility and usability of axisymmetric shape-change. First, we present 16 potential use cases for a cylindrical shape-changing display. Second, we present a two-month comparative field study in the workplace. Six participants had to shift energy consumption by using energy storage. To do so, they were notified about local energy forecasts. Compared with flat-screen animations, early results show that cylindrical shape-change animations keep a better attractiveness over time.
\end{abstract}

\section{CCS CONCEPTS}

- Human-centered computing $\rightarrow$ Displays and imagers; User studies.

\section{KEYWORDS}

Tangible User Interfaces, Data Physicalization, Shape-Changing Interfaces, Axisymmetric Shape-Change, Cylindrical Displays, Use cases, Field Study, Ambient Notifications, Longitudinal Notification, Renewable Energy, Demand-Side Management, Shifting Energy Demand, Behavior Change Support System, Assistive Technology

ACM Reference Format:

Maxime Daniel and Guillaume Rivière. 2021. Exploring Axisymmetric ShapeChange's Purposes and Allure for Ambient Display: 16 Potential Use Cases and a Two-Month Preliminary Study on Daily Notifications. In Fifteenth International Conference on Tangible, Embedded, and Embodied Interaction (TEI '21), February 14-17, 2021, Salzburg, Austria. ACM, New York, NY, USA, 6 pages. https://doi.org/10.1145/3430524.3442452

\section{INTRODUCTION}

Shape-Changing Interfaces (SCIs) hypothesize that physical objects will become as malleable as virtual objects $[7,13,15,16]$ : they promise to bridge the gap between the physicality of Tangible User

\author{
Guillaume Rivière \\ g.riviere@estia.fr \\ Univ. Bordeaux, ESTIA INSTITUTE OF TECHNOLOGY, \\ LaBRI, UMR 5800 \\ F-64210 Bidart, France
}

Interfaces (TUIs) and the flexibility of Graphical User Interfaces (GUIs). In the last decade, shape-changing interface research has focused on feasibility challenges rather than on utility and usability challenges $[1,11]$ : the usefulness and the user experience still need more in-depth exploration and understanding.

This paper focuses on the usefulness and the user experience of a cylindrical shape-changing display [5]. First, we explore potential utilities through 16 new use cases. Second, we compare the user experience between a shape-changing display and a graphical display over time. Two artifacts were used to support a new energy practice for two months in the workplace. Finally, we present the results, limitations, and lessons learned from this field study.

\section{RELATED WORK}

Axisymmetric (cylindrical) displays are readable at $360^{\circ}$ around the Y-axis: those displays can inform in the middle of open spaces such as public places, open-plans, or living rooms [2]. Previous work designed such dynamic displays as stacks of expandable disks. In 2010, Wu proposed a three-disk data display called WeatherLamp [19]. He designed WeatherLamp as a tangible ambient display of weather data on living spaces. Multivariate data were encoded using color, shape, sound, and animation. WeatherLamp allows user input when squeezing the disks. In 2012, Lakatos and Ishii proposed a five-disk shape display called Amphorm [9]. They designed Amphorm as a kinetic sculpture resembling a vase; gestural interaction around the vase allows user input to shape the sculpture. In 2019, Daniel et al. proposed a 10disk data display called CairnFORM [5]. CairnFORM uses both light-change and shape-change ${ }^{1}$ to notify energy forecast subtly on workplaces. They first studied the usability of CairnFORM as a 10ring-chart displaying ordinal data. Second, they studied notification in the periphery of vision and attention with ring-expansion: three ring-speed profiles were compared. Studying axisymmetric shapechanging displays on real-world tasks still needs exploration to deepen research knowledge in this area. Moreover, their application purposes are limited to weather data and energy data.

Purposes' exploration and field studies contribute to the grand challenges in shape-changing interface research [1]. First, assess the proper contexts of use, the fit between tasks and interfaces, and the issues around shape-change's cultural appropriation. Second, develop new applications (e.g., beyond Data Physicalization and

${ }^{1}$ Disks' diameters expand thanks to a mechanism actuating eight overlaying arcs that maintain a continuous circle-like border; these translucent PMMA-made-arcs are illuminated with RGB LEDs [4]. 
Peripheral Interaction) and content (e.g., beyond physicalizing weather data and energy data). The following section explores potential application-purposes of axisymmetric shape-change for display.

\section{USE CASES}

We organized two brainstorming sessions with four participants (two HCI experts and two engineering students). The aim was to explore new applications and content for axisymmetric shapechanging displays. In 2019, Alexander et al. [1] organized the purposes and the benefits of shape-change into five categories: (1) communicate information, (2) simulate objects, (3) hedonic and symbolic purposes, (4) adaptive affordance, and (5) augment users. The following subsections describe the applications we envisioned in the four first categories. We excluded the fifth category because we did not find applications for augmenting users.

\subsection{Communicate Information}

Daniel et al. [5] used axisymmetric shape-change in both ways: (1) cylindrical shape encodes ordinal data readable from $360^{\circ}$ around; (2) shape-change encodes data-transition. The resulting dynamic ring chart communicates renewable energy forecasts in public places (see figure 1a). Such dynamic ring charts could encode other data in public places: for example, encoding hour-per-hour weather forecast on the edge of a beach (see weather applications in Figures 1b, 1c, and 1d) to help attendees organizing their activities (e.g., sunbathing, swimming, windsurfing) without going back to their smartphones during holidays or hobbies; encoding slots' availability per floor at the first floor of a multistorey car park (see parking application in Figure 1e) and thus showing the least occupied floor (e.g., the 5th floor).

Axisymmetric shape and shape-change can represent animated icons. We imagined a Home Assistant Speaker (e.g., Google Home, Amazon Echo, Apple HomePod) in a living room integrating an axisymmetric shape-changing display. For example, representing an animated and illuminated yellow bell would inform inhabitants with hearing loss that someone is ringing at the door and a red one that the smoke detector is beeping (see security application in Figure 1f); an animated down or up loading-arrow would inform that the home assistant is unavailable because downloading an update or uploading a backup to the Internet (see system application in Figures $1 \mathrm{~g}$ and $1 \mathrm{~h}$ ); a colored battery would display the remaining level of local solar energy stored in the home's batteries (see battery management application in Figure 1i); a blinking top or bottom arrow would show whether a lost phone is above or under the existing floor (see orientation application in Figure 1j); a colored plus or minus symbol would indicate to players whether they are above or under the number to guess in the "more or less" game (see games application in Figure 1k).

\subsection{Simulate Objects}

Axisymmetric shape and shape-change can embody real-world axisymmetric objects and object-transformation. For example, a light bulb would illuminate an entrance hall (see flashlight application in Figure 2a); an hourglass would time baking in a kitchen (see timer application in Figure $2 b$ ); a set of Hanoï
Towers would illustrate puzzle-solving in a classroom (see puzzle application in Figure 2c).

\subsection{Hedonic and Symbolic Purposes}

Users may enjoy axisymmetric shape-change and color-change for its beauty and its emotional power. For example, dynamic sculptures such as a champagne fountain placed at the center of receptions would offer drinks (see champagne fountain application in Figure 3a); a Christmas tree placed in the hall of a mall would offer chocolates (see Christmas tree application in Figure 3b); a sound wave sculpture integrated into a central column of a concert room would visualize music frequencies (see music application in Figure 3c).

\subsection{Adaptive Affordance}

The following paragraphs present adaptive affordances for shapes and shape-changes for dynamic axisymmetric displays.

The speed profile of radius-changes could adapt accordingly to the application. Daniel et al. [5] show that speed-profile impact perception and detection: whereas an exponential speed profile notifies users subtly, a logarithmic speed profile alerts them. For example, the Home Assistant Speaker integrating axisymmetric shape-change display (see section 3.1) would use a logarithmic speed profile when morphing into an animated bell icon (see high priority notification application in Figure 1f); it would use an exponential speed profile when morphing into an animated download icon meaning unavailability (see low priority notification application in Figure 1g).

Shape-change-displays can also morph to change physical affordances. The Home Assistant Speaker integrating axisymmetric shape-change-display would switch from an application to another one. For example, the physical display would morph into an hourglass when the user asks for a 30-minute timer (see Figure 2b). While waiting for the timer to end, the user asks for his favorite music playlist. The physical display would morph to a dynamic sound-wave-sculpture visualizing the music's spectrogram (see Figure 3c). When the timer ends, the assistant pauses the music player, and the physical display morphs into a ringing bell (see Figure 1f).

The following section presents a field study of a real-world task.

\section{FIELD STUDY}

We focus on the purpose of communicating information on energy forecasts (see figure 1a). Users often get bored over time with the incentives trying to change their behavior. We hypothesize that shape-changes may help maintain users' interest by keeping attractiveness over time-like the ocean waves, the clouds in the sky, or the flames of an open fire. Better attractiveness over time would be beneficial to energy practices' assistance. We designed a new energy practice to optimize renewable energy consumption in workplaces: shifting laptops' consumption to peak hours of local renewable energy production using their batteries as renewable energy storage. Enabling this daily activity requires communicating renewable energy forecasts to the practitioners. We compared the communication of this information over time between an axisymmetric shape-changing display and a flat-screen. 


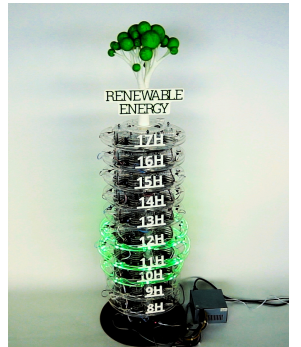

(a) Renewable energy forecast [5]

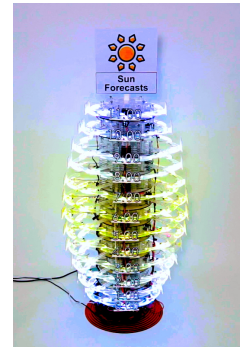

(b) Sun forecast

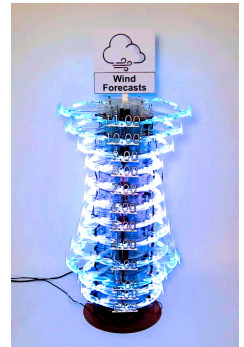

(c) Wind forecast

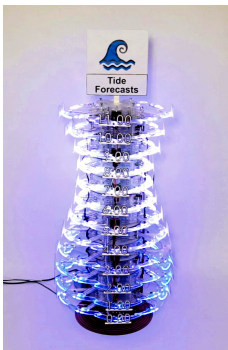

(d) Tide forecast

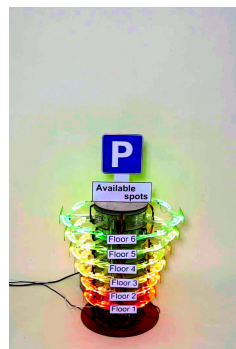

(e) Parking availability

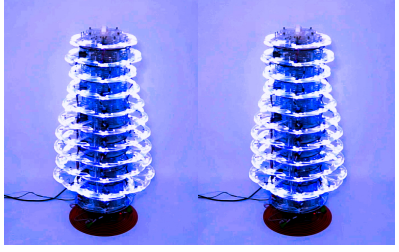

(f) Ringing Bell Animation

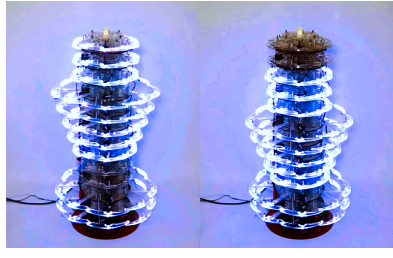

(g) Download Animation

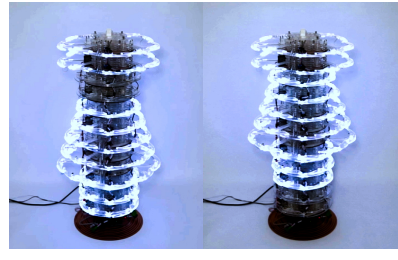

(h) Upload Animation

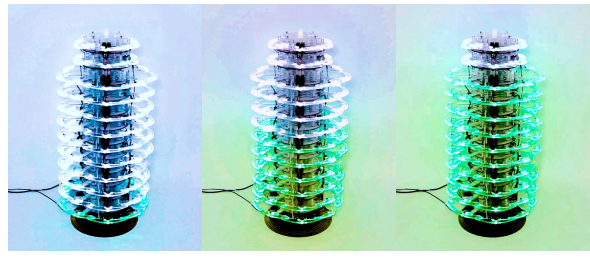

(i) Low, Medium, and Full Battery Levels

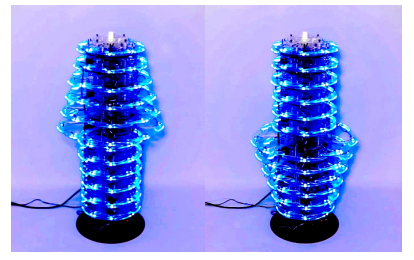

(j) Up and Down Arrows

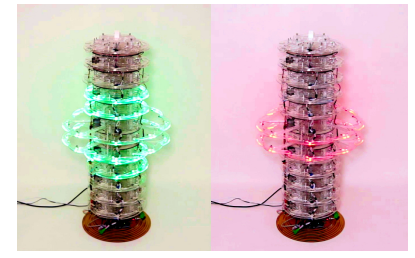

(k) Plus and Minus Operators

Figure 1: Examples of applications communicating information.

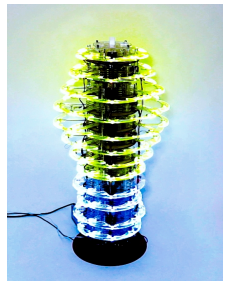

(a) Light Bulb

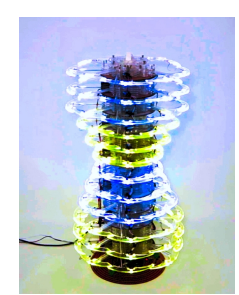

(b) Hourglass

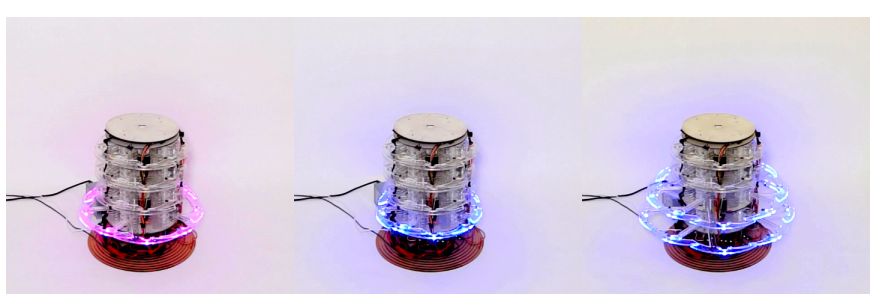

(c) Hanoï Towers

Figure 2: Examples of applications simulating real-world objects.

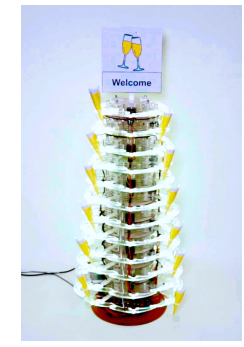

(a) Champagne Fountain

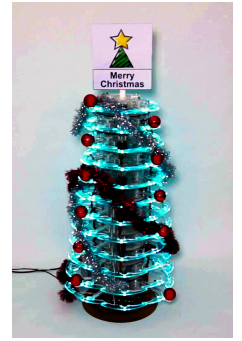

(b) Christmas Tree

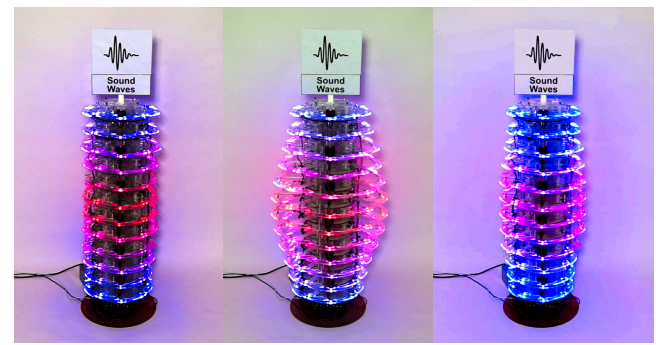

(c) Sound Wave Sculpture

Figure 3: Examples of applications with dynamic sculptures. 
The following subsections describe the conditions and results of a two-month field study in the workplace.

\subsection{Participants, Task, and Modalities}

The six participants were Ph.D. students from our laboratory, divided into two groups of three persons in separate open-plans (each group was one woman and two men, Md 20-29 years old, $\mathrm{Md}$ 5 th year university degree). During two months, the participants tried shifting their laptop's battery charging at work. We placed two artifacts visualizing 10-hour forecasts on the availability of local renewable energy (see Figure 4): (a) the shape-changing cylindrical display CairnFORM and (b) a flat-screen display. Both artifacts displayed energy forecast updates with a vertical histogram. Each ring or bar of the histograms was associated with an hour (from 8:00 to 17:59). Rings' diameters (from $30 \mathrm{~cm}$ to $60 \mathrm{~cm}$ ) or bars' length (from $13 \mathrm{~cm}$ to $26 \mathrm{~cm}$ ), and green intensity (from $0 \%$ to $100 \%)$ represented solar energy production capacity during an hour (from $0 \mathrm{Wh}$ to $5 \mathrm{kWh}$ ). A blue intensity was used instead of green intensity to represent the current hour. A ring's or bar's color changed from green to white to show the office team's highest battery charge done in the day. Whiteness was correlated with the hour's charge depth (up to $50 \%$ of battery level). The users had to place or remove their batteries and plug or unplug the power supply charger according to ascending and descending hours of renewable energy variations ${ }^{2}$. For better understanding, energy variations were displayed one-after-another [5]. When the current variation's last ring or bar became blue, the next variation was displayed: a sequential bottom-up animation was then opening new rings or bars (like a smooth fade-in). In the first week, the current energy variation was updated every 15 minutes according to new forecasts. From the second week to the eighth week, energy variations were not updated once displayed.

\subsection{Apparatus and Procedure}

The two artifacts were placed in two open-plans of our research laboratory. The two artifacts were readable by all the participants once sat down at their desks. A tracker program was installed on each laptop to log the participant's identity, presence, and battery usage; these data were sent to a remote server every 15 minutes. The remote server updated forecasts every 30 minutes using a renewable energy management service ${ }^{3}$. The two artifacts were controlled each by a Raspberry Pi 3 connected by Ethernet to the Internet. Every 15 minutes, the Raspberry Pi 3 requested the remote server for forecast update and animated the displays if necessary (the first week only). Audio speakers played sound during animations under the flat display conditions to counterbalance the shape-changing display's noise when animated (because of motors and mechanisms). In each office, a shared notebook allowed the participants to write down comments.

The experiment went through four phases. (1) Control Phase (two weeks): each participant signed a consent form, and the tracker was installed on each laptop. (2) Preparation Phase (one day): during a meeting, the participants were told that battery charges are usually

\footnotetext{
${ }^{2}$ An energy variation starts from a minimum energy availability (local minimum or global minimum), increases until a maximum (local maximum or global maximum), and decreases until the following minimum (local minimum or global minimum) [5]. ${ }^{3}$ Hourly photovoltaic production forecast service: https://www.epices-energie.fr/
}

not synchronized with renewable energy sources' availability. They were introduced to a vertical histogram that could help them synchronizing their battery charge with solar energy availability in the building. The participants were told that an artifact displaying the histogram would be deployed for two months in their open-plan. A shared notebook would be at their disposal to write down their comments. They would also answer two semi-structured interviews. (3) Deployment Phase (eight weeks): the two artifacts were deployed in the open-plans. After one week, a semi-structured interview with each participant gathered initial feedback on the experiment. (4) Retreat Phase (one day): artifacts were removed from the openplans. The tracking program was uninstalled from the laptops. A semi-structured interview with each participant gathered final feedback on the experiment.

\subsection{Measurements and Questionnaires}

A tracker program was developed to watch the completion of the task. Every 15 minutes, the program recorded the timestamp, the user identity (the username of the Windows/Linux/macOS session), the office presence (scan and detect the Wi-Fi access points of the open-plan), and the battery events (level and status from the battery management system of Windows/Linux/macOS). The program sent these data to the remote web server by Wi-Fi or Ethernet over the Internet if available. If the Internet is not available, the program stores the data in a file and tries to send them again every 15 minutes. Participants had to write down any comment about the experiment on a shared notebook (one in each open-plan). During semi-structured interviews, participants had to fill in two forms: (1) the New Ecological Paradigm (NEP) scale [6] to assess if the completion of the task was influenced by pro-environmental values (i.e., intrinsic motivation); (2) the Short User Experience Questionnaire (UEQ-S) [12] to assess if the completion of the task was influenced by user experience with the artifact (i.e., extrinsic motivation). Questions were also asked about the artifacts (e.g., "Does the artifact attracted your attention? If yes, when and how?"), about the energy practice (e.g., "Did you try to shift your laptop battery charge? If yes, how many times? What steps did you follow?"), and about their motivation (e.g., "During the experiment, were you more motivated by using the artifact or reducing your consumption of non-renewable energy?").

\subsection{Results and Discussion}

The answers to the questionnaires suggest that: (1) the energy practice is simple, relevant at work, and aligned with the participant's pro-environmental values, which were not influenced by the displays; (2) the shape-changing display is as pragmatic as the flat-screen after two months; (3) the shape-changing display is still more hedonic than the flat-screen after two months. Several factors, however, limit these results: previous comments on the shared notebook may have influenced the participants; participants were in the same building and may have talked about the experiment over time: written and oral comments might then have a bias; the low number of six participants prevent analyzing observed data with inferential statistics. More parameters should also have been logged to compute actual energy savings, to assess the energy practice's 


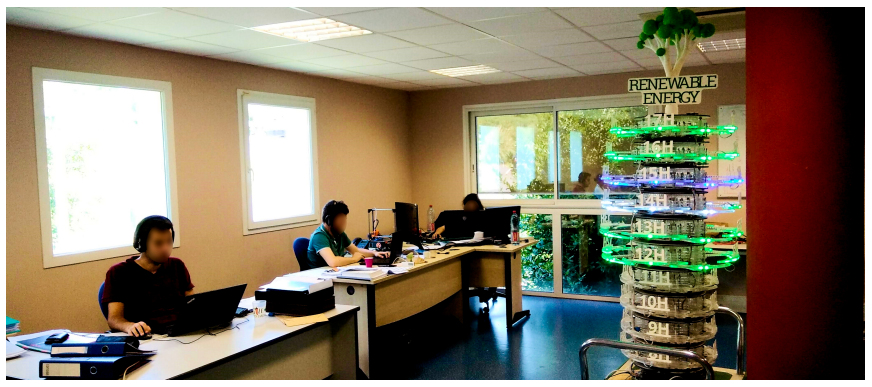

(a) Axisymmetric shape-changing display

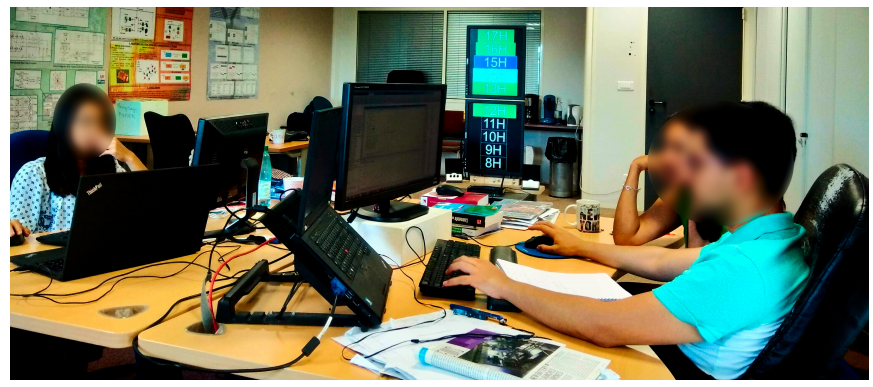

(b) Flat-screen display

Figure 4: The two artifacts placed in the two open-plans.

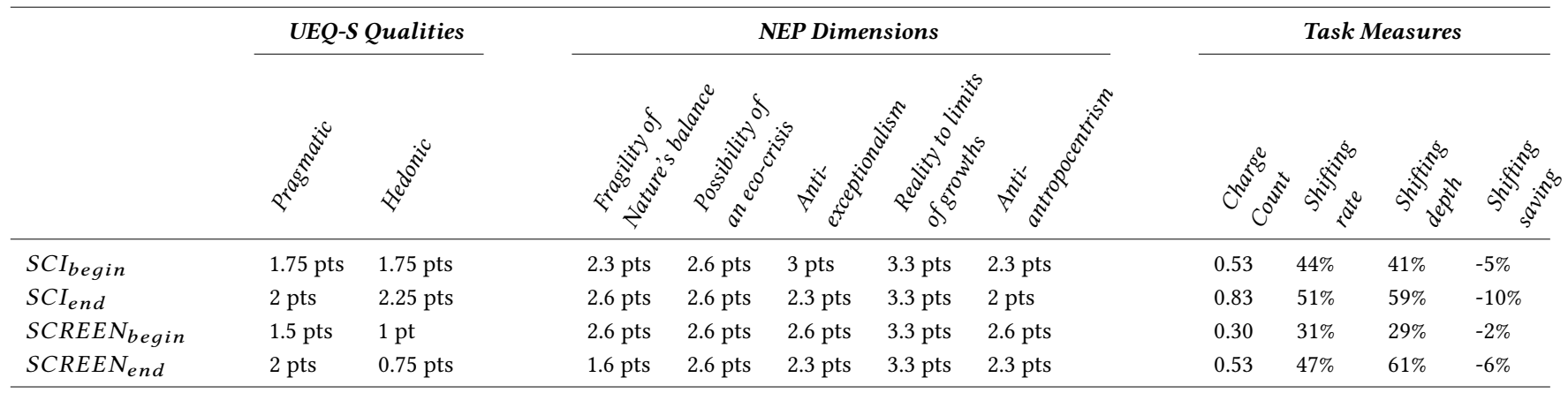

Table 1: Mean values for the two qualities of UEQ-S, the five dimensions of the NEP scale, and the four task completion measurements at the beginning (first week) and the ending (eighth week) of the experiment for the two artifacts.

worthwhileness. The following paragraphs describe the results of the field study.

Pro-environmental Goal. NEP-scale's results (see Table 1) show that the experiment did not change pro-environmental values. Participants highlighted the relevance of the task at work (P2: "The practice is interesting. This is the first time I get the opportunity to charge my battery during optimal periods [of local solar energy production]. We can do another positive thing at work [for the environment]"). Participants also highlighted the simplicity of the task at work (P5: "The practice costs almost nothing. I do not need to move from my office. I just have to plug or unplug my laptop"). One participant stated that the artifact was an original way to explain the fluctuation of renewable energy sources (P6: "Innovative for understanding how works the generation of renewable energy. It is a good manner to teach people that there are moments when energy is cleaner"). Another participant appreciated that the artifacts served as a green nudge [18] (P4: "I liked that the prototype reminds us that we can contribute to being more ecological ones").

Pragmatic Quality and Task Performance. UEQ-S's results (see Table 1) show that both the shape-changing display (Pragmatic $_{\text {begin }} 1.75$ pts, Pragmatic $_{\text {end }} 2$ pts, $+14 \%$ ) and the flatscreen (Pragmatic $_{\text {begin }} 1.5$ pts, Pragmatic $_{\text {end }} 2$ pts, $+33 \%$ ) became more pragmatic over time (i.e., learning effect). Written and oral comments show that it was difficult to use the artifacts for the task at the beginning; users got around these difficulties through social interactions (P6: "At the beginning, it was difficult to understand when we had to unplug the laptop. After several days of usage and discussions with the colleagues of the office, I understood"). The results also show that the two displays were rated equally pragmatic at the end (Pragmatic end $_{2} 2 \mathrm{pts}$ ). The task measurements (see Table 1) support that task performance was better at the end (for both shifting rates and shifting depth), but these results should be analyzed regarding tasks' completion opportunities to assess the energy practice's worthwhileness (logged parameters are insufficient for further analysis). These results also show that the two artifacts performed equally at the end (51\% vs $47 \%$ shifting rates, $59 \%$ vs $61 \%$ shifting depth, for the shape-changing interface vs the flat-screen). The practice performance was, however, affected by a lack of reliability in solar energy production forecasts (P5: "Sometimes the forecast was updated after I already started to discharge my battery. So, I had to plug my laptop during an off-peak hour"). The 15-minute-updates of the current variation were stopped after the first week. Instructions should be designed to drive users when facing wrong forecasts.

Hedonic Quality. Participants felt sadness when the artifacts did not announce solar energy production (P2: "It was depressing, the days in which the prototype was not illuminated"); participants felt happiness when the artifacts announced solar energy production (P5: "When it is green, we are happy because we know that it will 
be sunny in the day"). Weather conditions are known to affect human humor [3, 8]. The two artifacts convey strong emotions (sadness or happiness), but these emotions may be caused by the visualized forecast of local solar energy production, which is tied to sunshine weather conditions (P2: "The only means to be in touch with the outside in the office, was to look at the windows. With the prototype, we had another contact with the outside"). UEQ-S's results (see Table 1) show that the shape-changing interface was rated more hedonic than the flat-screen initially (i.e., novelty effect); this contrast increased over time. Whereas the flat-screen's hedonic quality decreased by $25 \%$ over the two months (Hedonic begin $_{\text {in }}$ $1 \mathrm{pt}$, Hedonic $_{\text {end }} 0.75 \mathrm{pts}$ ), the shape-changing interface's hedonic quality increased by $29 \%$ (Hedonic $_{\text {begin }} 1.75$ pts, Hedonic end $_{\text {en }}$ $2.25 \mathrm{pts}$ ). The axisymmetric shape-change display seems to convey endless fascination over time (P2: "When the forecast is updated, I cannot resist watching the animation until the end"); this echoes with previous work that links shape-change with the experience of particular feelings $[10,14,17]$. Getting endless fascination is useful to maintain the artifact allure. This allure may be useful to assist energy practices over time.

\section{CONCLUSION AND FUTURE WORK}

Exploring the usefulness and understanding the user experience of shape-change are grand challenges. This paper extends the potential utility of axisymmetric shape-change for display: we report 16 new use cases illustrating four of the five shape-changing purposes. Promising future work would improve the expansion range, motion noise, and motion speed of the rings' mechanism, for example, to implement the sound wave sculpture. This paper also extends the understanding of the user experience with axisymmetric shapechange for display. We compared two artifacts displaying local solar energy production forecasts: six employees had to charge laptops' batteries during peak hours. After two months, the axisymmetric shape-changing display and the flat-screen were rated equally pragmatic. Whereas the flat-screen's hedonic quality decreased by $25 \%$, the shape-changing display's hedonic quality increased by 29\%: shape-change seems to convey endless fascination over timelike the ocean waves, the clouds in the sky, or the flames of an open fire. The lessons learned and the promising early results validate the start of a six-month study with more participants: to assess to what extent shape-changing displays are suitable for longitudinal notification; to assess whether the energy practice is worthwhile.

\section{ACKNOWLEDGMENTS}

The authors thank Adrien Fat Cheung and Gauthier Capdepon de Bigu for their participation in the brainstorming sessions during their internship.

\section{REFERENCES}

[1] Jason Alexander, Anne Roudaut, Jürgen Steimle, Kasper Hornbundefinedk, Miguel Bruns Alonso, Sean Follmer, and Timothy Merritt. 2018. Grand Challenges in Shape-Changing Interface Research. In Proceedings of the 2018 CHI Conference on Human Factors in Computing Systems (Montreal QC, Canada) (CHI '18). Association for Computing Machinery, New York, NY, USA, Article 299, 14 pages. https://doi.org/10.1145/3173574.3173873

[2] Carmelo Ardito, Paolo Buono, Maria Francesca Costabile, and Giuseppe Desolda. 2015. Interaction with Large Displays: A Survey. ACM Comput. Surv. 47, 3, Article 46 (Feb. 2015), 38 pages. https://doi.org/10.1145/2682623
[3] Michael R. Cunningham. 1979. Weather, mood, and helping behavior: Quasi experiments with the sunshine samaritan. Fournal of Personality and Social Psychology 37, 11 (1979), 1947-1956. https://doi.org/10.1037/0022-3514.37.11.1947

[4] Maxime Daniel, Guillaume Rivière, and Nadine Couture. 2018. Designing an Expandable Illuminated Ring to Build an Actuated Ring Chart. In Proceedings of the Twelfth International Conference on Tangible, Embedded, and Embodied Interaction (Stockholm, Sweden) (TEI '18). Association for Computing Machinery, New York, NY, USA, 140-147. https://doi.org/10.1145/3173225.3173294

[5] Maxime Daniel, Guillaume Rivière, and Nadine Couture. 2019. CairnFORM: A Shape-Changing Ring Chart Notifying Renewable Energy Availability in Peripheral Locations. In Proceedings of the Thirteenth International Conference on Tangible, Embedded, and Embodied Interaction (Tempe, Arizona, USA) (TEI '19). Association for Computing Machinery, New York, NY, USA, 275-286. https://doi.org/10.1145/3294109.3295634

[6] E. Dunlap Riley, D. Van Liere Kent, G. Mertig Angela, and E. Jones Robert. 2000. New Trends in Measuring Environmental Attitudes: Measuring Endorsement of the New Ecological Paradigm: A Revised NEP Scale. Journal of Social Issues 56, 3 (2000), 425-442. https://doi.org/10.1111/0022-4537.00176

[7] Hiroshi Ishii, Dávid Lakatos, Leonardo Bonanni, and Jean-Baptiste Labrune. 2012. Radical Atoms: Beyond Tangible Bits, toward Transformable Materials. Interactions 19, 1 (Jan. 2012), 38-51. https://doi.org/10.1145/2065327.2065337

[8] Matthew C. Keller, Barbara L. Fredrickson, Oscar Ybarra, Stéphane Côté, Kareem Johnson, Joe Mikels, Anne Conway, and Tor Wager. 2005. A Warm Heart and a Clear Head: The Contingent Effects of Weather on Mood and Cognition. Psychological Science 16, 9 (2005), 724-731. https://doi.org/10.1111/j.14679280.2005.01602.x

[9] Dávid Lakatos and Hiroshi Ishii. 2012. Towards Radical Atoms - Form-giving to transformable materials. In 3rd IEEE International Conference on Cognitive Infocommunications (CogInfoCom) (Kosice, Slovakia). IEEE, 37-40. https://doi. org/10.1109/CogInfoCom.2012.6422023

[10] Esben W. Pedersen, Sriram Subramanian, and Kasper Hornbundefinedk. 2014. Is My Phone Alive? A Large-Scale Study of Shape Change in Handheld Devices Using Videos. In Proceedings of the SIGCHI Conference on Human Factors in Computing Systems (Toronto, Ontario, Canada) (CHI '14). Association for Computing Machinery, New York, NY, USA, 2579-2588. https://doi.org/10.1145/ 2556288.2557018

[11] Majken K. Rasmussen, Esben W. Pedersen, Marianne G. Petersen, and Kasper Hornbundefinedk. 2012. Shape-Changing Interfaces: A Review of the Design Space and Open Research Questions. In Proceedings of the SIGCHI Conference on Human Factors in Computing Systems (Austin, Texas, USA) (CHI '12). Association for Computing Machinery, New York, NY, USA, 735-744. https://doi.org/10. 1145/2207676.2207781

[12] Martin Schrepp, Andreas Hinderks, and Jörg Thomaschewski. 2017. Design and Evaluation of a Short Version of the User Experience Questionnaire (UEQ-S). International fournal of Interactive Multimedia and Artificial Intelligence 4, 6 (2017), 103-108. https://doi.org/10.9781/ijimai.2017.09.001

[13] Orit Shaer and Eva Hornecker. 2010. Tangible User Interfaces: Past, Present, and Future Directions. Found. Trends Hum.-Comput. Interact. 3, 1-2 (Jan. 2010), 1-137. https://doi.org/10.1561/1100000026

[14] Paul Strohmeier, Juan Pablo Carrascal, Bernard Cheng, Margaret Meban, and Roel Vertegaal. 2016. An Evaluation of Shape Changes for Conveying Emotions. In Proceedings of the 2016 CHI Conference on Human Factors in Computing Systems (San Jose, California, USA) (CHI '16). Association for Computing Machinery, New York, NY, USA, 3781-3792. https://doi.org/10.1145/2858036.2858537

[15] Paul Strohmeier, Antonio Gomes, Giovanni Maria Troiano, Aske Mottelson, Timothy Merritt, and Jason Alexander. 2016. Sharing Perspectives on the Design of Shape-Changing Interfaces. In Proceedings of the 2016 CHI Conference Extended Abstracts on Human Factors in Computing Systems (San Jose, California, USA) (CHI EA '16). Association for Computing Machinery, New York, NY, USA, 3492-3499. https://doi.org/10.1145/2851581.2856478

[16] Ivan E. Sutherland. 1965. The ultimate display. Multimedia: From Wagner to virtual reality 1 (1965).

[17] Haodan Tan, John Tiab, Selma Šabanoviundefined, and Kasper Hornbundefinedk. 2016. Happy Moves, Sad Grooves: Using Theories of Biological Motion and Affect to Design Shape-Changing Interfaces. In Proceedings of the 2016 ACM Conference on Designing Interactive Systems (Brisbane, QLD, Australia) (DIS '16). Association for Computing Machinery, New York, NY, USA, 1282-1293. https: //doi.org/10.1145/2901790.2901845

[18] Richard H. Thaler and Cass R. Sunstein. 2008. Nudge: Improving Decisions About Health, Wealth, and Happiness. Yale University Press, New Haven, CT, USA. https://doi.org/10.1002/bdm.652

[19] Andy Wu. 2010. Tangible Visualization. In Proceedings of the Fourth International Conference on Tangible, Embedded, and Embodied Interaction (Cambridge, Massachusetts, USA) (TEI '10). Association for Computing Machinery, New York, NY, USA, 317-318. https://doi.org/10.1145/1709886.1709961 